\title{
Dynamic Characteristic Analysis of Indirect Carbon Emissions Caused by Chinese Urban and Rural Residential Consumption Based on Time Series Input-Output Tables from 2002 to 2011
}

\author{
Guoxing Zhang, Mingxing Liu, and Xiulin Gao \\ School of Management, Lanzhou University, Lanzhou 730000, China \\ Correspondence should be addressed to Mingxing Liu; fivestars1212@gmail.com
}

Received 26 December 2013; Accepted 22 February 2014; Published 31 March 2014

Academic Editor: Chuangxia Huang

Copyright (c) 2014 Guoxing Zhang et al. This is an open access article distributed under the Creative Commons Attribution License, which permits unrestricted use, distribution, and reproduction in any medium, provided the original work is properly cited.

\begin{abstract}
Carbon emissions caused by residential consumption have become one of the main sources of carbon emission and revealed a huge growth trend in China. By processing data of Chinese input-output tables available and relative Statistical Yearbook, this paper uses RAS method to update the input-output tables to obtain the time series input-output tables from 2002 to 2011 . Then, we use input-output method to make a contrastive analysis of changes in carbon emissions caused by Chinese rural and urban residents' consumption. The results show that the indirect carbon emission caused by urban residents' consumption is the main part of carbon emission caused by residents' consumption, and the gap between carbon emission caused by urban and rural residents' consumption is wider and wider. The annual per capita indirect carbon emissions in urban and rural areas increase by years, and the increment of the town is much greater than that of the country. At last, we analyze carbon emissions from residents' consumption by sectors and obtain some meaningful results. In accordance with the above conclusions, the paper puts forward some countermeasures and suggestions from consumer behaviors, structure of consumption, energy usage, and so on.
\end{abstract}

\section{Introduction}

Since the 1980s, China's population scale, the proportion of urban and rural, income level, and consumption patterns have undergone significant changes, and these changes have a great impact on the carbon emissions caused by the residential consumption. For a long time, scholars usually focused on industrial fields and considered them from the view of production as to climate warming but ignored the residential consumption which is the original driving force of producing activities. A large number of recent studies indicate that indirect carbon emissions produced by residents' living consumption should not be overlooked which has become one of the main sources of carbon emissions in China and has a huge growth trend. For example, Wang and Shi's [1] research points to the fact that China's carbon emissions caused by residential consumption account for $30 \%$ of the total carbon emissions in 2004, up from $19 \%$ in 1995. Researches of Liu et al. [2], Zha et al. [3], Fan et al. [4] show that, in recent years, carbon emissions caused by Chinese urban and rural residents' consumption increase by years. Therefore, it is significant to make a detail research about carbon emissions caused by Chinese urban and rural residents' consumption and put forward corresponding measures and suggestions.

Currently, scholars from various countries have used different approaches to study about carbon emissions generated by the residents' consumption since it is getting more and more attention. There are two common methods. One is to calculate the carbon emissions led by residential consumption on the basis of direct and indirect energy consumption due to residents' several common way of life. For example, Feng et al. [5] use this method to quantify the Chinese urban residents' direct and indirect energy consumption and its dynamic features from 1999 to 2007 and analyze the potential impact factors. Zha et al. [3] compute and compare the changes of carbon emissions induced by Chinese urban and rural residents' energy consumption from 1991 to 2004 and combine with index decomposition method to study 
the internal factors. Fan et al. [4] calculate carbon emissions according to different energy consumption through residents' five kinds of common way of life and use decomposition method to analyze the driving factors from the perspective of final demand from 1996 to 2008. Yao et al. [6] use this method to analyze Chinese rural residential energy consumption and carbon emissions from 2001 to 2008. The result shows that during this period, the carbon emissions caused by rural residential energy consumption increased significantly, and the annual growth rate of per capita carbon emissions was nearly 2 times faster than that of urban area. Liu et al. [7] and Liang et al. [8] measure the carbon emissions produced by rural residential consumption in north China according to several consumer behaviors and analyze the characteristics and structure of low-carbon development in country. Feng et al. [9] and Wei et al. [10] study the carbon emissions caused by Chinese urban and rural residents' consumption on the basis of statistical data of residents' energy consumption from several consumer behaviors. Bin and Dowlatabadi [11] use this method to study the United States' carbon emissions distribution caused by consumer activities. Abu-Madi and Abu Rayyan [12] use this method to study the carbon dioxide emissions in Palestine. Munksgaard et al. [13] calculate Denmark's carbon emissions according to the direct and indirect energy consumption produced by residents' several common ways of life between 1966 and 1992 and analyze the reasons for the increase of carbon emissions through structure decomposition method. The studies above can calculate the carbon emissions generated by urban and rural residents' consumption according to the energy consumption by the residents' several common ways of life, but the consumer activities they involve are only limited to the food, electricity, water, heating, and other common projects and cannot embrace all aspects of life. Particularly, when calculating the indirect carbon emissions produced by consumers, this kind of method is more insufficient. In addition, it's impossible to link residents' consumption with the corresponding sectors.

Another approach is input-output method. For example, Zhu et al. [14] investigate the indirect carbon emissions caused by residential consumption in China from 1992 to 2005 on the basis of the input-output model and examine the factors through the structural decomposition method. The result shows that the rise of the level of residential consumption plays a dominant role in the growth of residential indirect carbon emissions and the persistent decline of the carbon emission intensity of industrial sectors restrains the total carbon emissions. Zhang [15] uses input-output analysis and decomposition techniques to examine Chinese urban and rural per capita carbon emissions from 1987 to 2007. Liu et al. [2] determine the carbon emissions induced by urban and rural residential consumption by the inputoutput method, and the result demonstrates that the direct and indirect carbon emissions from residential consumption accounted for more than $40 \%$ of total carbon emissions between 1992 and 2007. Fan et al. [16] use an input-output model and urban consumer data from 2003 to 2009 in China to check personal embedded carbon footprint and its evolvement rule. Based on input-output model, Chen et al.
[17] investigates Beijing's carbon emissions in 2007. Cellura et al. [18] assess the indirect energy consumption and carbon emissions related to Italian residential consumption on the basis of energy and environment input-output model and structural decomposition analysis and analyze the factors that influence the change of carbon emissions. Aparna and Saikat [19] estimate the direct and indirect carbon emissions produced by Indian's households by using input-output analysis and study the affecting factors on the change of carbon emissions between 1993 and 2006 through decomposition method. Park and Heo [20] and Cohen et al. [21] use inputoutput method to calculate the direct and indirect energy needed in South Korea and Brazil, respectively. The studies above are all based on the input-output tables for a given year to study carbon emissions caused by residential consumption without calculating year by year. And the researches mainly emphasize the simple analysis of affecting factors of carbon emissions, but lack deep understanding on structure and characteristics of carbon emissions generated by households' energy consumption. For a detailed understanding about the carbon emissions caused by Chinese urban and rural residential consumption in recent ten years, we will calculate the indirect carbon emissions produced by residential consumption from 2002 to 2011. Firstly, we rearrange the Chinese input-output tables available by using RAS method. Secondly, we calculate each year's indirect carbon emissions produced by residential consumption in accordance with the time series input-output tables and do some corresponding analysis. Finally, we examine the consumption structure and characteristics of carbon emissions produced by Chinese urban and rural residential consumption from the point of industries to put forward the corresponding measures and suggestions.

\section{Methodology and Data Source}

2.1. Updating Input-Output Tables. It is difficult to compile a table every year for a lot of manpower, material resources, and time needed and time delay. So far, Chinese inputoutput table was compiled every five years, namely, at the year with the last number being 2 or 7 , and the extended input-output tables are compiled at the year with the last number being 0 or 5 . Therefore, many scholars have done a lot of research to update and estimate the data of inputoutput tables (which are compiled in the years in which the government do not participate to do so). Looking through the related literatures for more than 70 years, researchers have proposed dozens of nonsurvey or partial survey methods $[22,23]$, but the most important and widely used are the RAS method and entropy method [24]. This paper will use the former to estimate the data of input-output tables in vacant years in China between 2002 and 2011. Though the delay in carbon emissions produced by residential consumption, Huang et al. [25] research suggests that a fixed-time delay models of a dynamic economy can explain various complex dynamic behaviors of the economic variables, so, the study of this paper may explain the dynamic characteristics of carbon 
emissions caused by Chinese residential consumption very well.

The basic idea of RAS is to regard the total intermediate demand of the target year as the lateral control variable and the total intermediate input of the target year as the longitudinal control variable and to revise the intermediate input structure of the base year to obtain the input-output flow matrix of the target years. It was first proposed by the famous British economist Stone et al. in 1960. After that, this method was studied and improved by many other scholars [26-30]. The specific operation can be divided into the following steps. (1) Calculate the direct consumption coefficient matrix of the base year in accordance with the base year's input-output table. (2) Multiply the total output of the target year by the direct consumption coefficient matrix of the base year to get an input matrix and to calculate the row sum. Then divide the column of the total intermediate demand of the target year by the corresponding row sum of the input matrix to get the row ratio. (3) Multiply the row ratio by the each data of the corresponding row of the input matrix we have got in the second step. So, we adjust the row sums of the matrix equal to the column of the total intermediate demand of the target year, while the column sums of the matrix is not equal to the row of the total intermediate input of the target year. (4) The same method is used to calculate the column ratio, then multiply the column ratio by each datum of the corresponding column of the input matrix we have got in the third step, so we adjust the column sums of the matrix equal to the row of the total intermediate input of the target year, while the row sums of the matrix is not equal to the column of the total intermediate input of the target year. Next, we keep repeating the third and fourth steps, into the iterative process, until the row sums of the matrix and the column sums of the matrix are equal to the column of the total intermediate demand and the row of the total intermediate input of the target year. The matrix we get at last is the first quadrant matrix in the input-output table of the target year. The same idea can be applied to update the second and third quadrant matrix.

In this paper, the data foundation to update Chinese input-output tables is the 42 departments' input-output tables in 2002, 2005, 2007 and 2010. And the total output of various departments, the added value of various departments, the total consumption of rural and urban residents, government consumption expenditure, gross fixed capital formation, increase in inventories, total exports and total imports between 2002 and 2011. The data of input-output tables are derived from China Statistics Bureau website [31] and others are from corresponding Chinese Statistical Yearbook [32]. Because the classification of the department in the inputoutput table is different from that of Statistical Yearbook, we set the following 31 departments to take into account both of the sectoral classification by considering the adjustment in "National Industry Classification" (GB/T4754-2002) (see Table 1). Among them, other manufacturing industry include recycling and disposal of waste; other services include information transmission, computer services and software industry, leasing and business services, tourism, scientific research career, integrated technology services, other social services,
TABLE 1: Sectoral classification of the input-output tables.

Farming, forestry, animal husbandry, fishery, and water conservancy

2 Mining and washing of coal

3 Extraction of petroleum and natural gas

$4 \quad$ Mining and processing of metal ores

$5 \quad$ Mining and processing of nonmetal ores

6 Manufacture of foods and tobacco

7 Manufacture of textile

8 Manufacture of wearing apparel, leather, feather, and related products

9 Processing of timber, manufacture of furniture

10

Printing and manufacture of articles for culture and education

11 Processing of petroleum, coking, processing of nuclear fuel

12 Manufacture of chemical products

13 Manufacture of nonmetallic mineral products

14 Smelting and pressing of metals

15 Manufacture of metal products

16 Manufacture of general and special purpose machinery

17 Manufacture of transport equipment

18 Manufacture of electrical machinery and equipment

19 Communication equipment, computers, and other electronic equipment

Manufacture of measuring instruments and machinery for cultural activity and office work

21 Other manufacturing

Production and distribution of electric power and heat power

23 Production and distribution of gas

24 Production and distribution of water

25 Construction

26 Transport and storage postal service

27 Wholesale and retail trade

28 Hotel and restaurants

29 Finance and insurance

30 Real estate

31 Other services

education, hygiene, social security and social welfare, culture, sports and entertainment, and public administration and social organizations; transport storage and post are combined into transport and storage postal service.

Next, we will introduce how to estimate the control vector of the target year and select the base year. Total output minus the added value is the total intermediate inputs, and the total output minus the end use is the total intermediate use. So we must first estimate the total output, value added, and the end use. In addition, the statistical caliber of relevant data in yearbooks is different from that in input-output tables. Therefore, when estimating the control vector of the target year, we should do some work to make the caliber of the data the same. The general adjustment method is to calculate 
the ratio of the total output from input-output table of the base year and that from yearbooks and to adjust the ratio of the total output from Statistical Yearbook in the target year. As for selecting base year, the nearby principle is employed, and we make full use adjacent input-output tables rather than extend input-output tables. That is 2003 and 2004 are calculated by the 2002 input-output table, 2006, 2008, and 2009 are calculated by the 2007 input-output table, and 2011 is calculated by the 2010 extend input-output table. Besides, current price is used in the process of calculation.

Next, we will use the data of input-output tables from 2002 to 2011 to calculate the total indirect carbon emissions generated by the rural and urban residential consumption, per capita carbon emissions, and carbon emissions of each department.

\subsection{Calculation of Indirect Carbon Emissions Caused by} Residential Consumption Based on Input-Output Model. An input-output model is a quantitative economic technique that represents the interdependencies between different departments of an economy and it reflects the effects of changes in one industry on others or the effects of consumers by solving a set of matrix equations. So, this model is highly appropriate for a study on indirect carbon emissions from residential consumption, and the formula is as follows:

$$
\mathrm{CE}_{c}=E(I-A)^{-1} R_{c}(c=0,1),
$$

where CE is the row vector for indirect carbon emissions from various products of residential consumption, the sums of the row vector are the total indirect carbon emissions generated by residential consumption. The subscript $C$ is used to distinguish the consumption of urban and rural residents. When it is equal to 0 , it represents rural resident, and when it is equal to 1 , it represents urban resident. $E$ is the row vector for the carbon emissions per unit of gross output of each industrial sector in the input-output tables. $I$ is the identity matrix, $A$ is the direct consumption coefficient of the input-output table. $(I-A)^{-1}$ is the Leontief inverse matrix, $R$ is the diagonal matrix converted from the column vector of residential final consumption in input-output tables. The calculation formula for the carbon emissions per unit of gross output of each industrial sector are as follows:

$$
E_{i}=\frac{\sum_{j} M_{i j} K_{j}}{T_{i}},
$$

where $E_{i}$ represents the carbon emissions per unit of gross output of sector $i . M_{i j}$ represents the sector $i$ 's consumption of the $j$ th kind of fuel. $K_{j}$ is the carbon emission factors of the $j$ th kind of fuel. $T_{i}$ is the gross output of the sector $i$.

To calculate the indirect carbon emissions from residential consumption, the data mainly from 2002 to 2011 time series input-output tables and the carbon emissions per unit of gross output of each sector in the input-output tables. The former has been estimated and the latter can be calculated by (2). Though China has no statistical data for carbon emissions of each sector, there are statistical data for a variety of energy consumption by sectors and carbon emissions are mainly
TABLE 2: Carbon emission factors of energy sources.

\begin{tabular}{lc}
\hline Coal & $0.5183(\mathrm{kgc} / \mathrm{kg})$ \\
Coke & $0.7801(\mathrm{kgc} / \mathrm{kg})$ \\
Crude oil & $0.8237(\mathrm{kgc} / \mathrm{kg})$ \\
Gasoline & $0.7978(\mathrm{kgc} / \mathrm{kg})$ \\
Kerosene & $0.8231(\mathrm{kgc} / \mathrm{kg})$ \\
Diesel oil & $0.8443(\mathrm{kgc} / \mathrm{kg})$ \\
Fuel oil & $0.8647(\mathrm{kgc} / \mathrm{kg})$ \\
Natural gas & $0.5897\left(\mathrm{kgc} / \mathrm{m}^{3}\right)$ \\
Electricity & $0.2602(\mathrm{kgc} / \mathrm{kw} \cdot \mathrm{h})$ \\
\hline
\end{tabular}

derived from a variety of energy consumption. Therefore, this paper calculates the direct carbon emissions of each sector based on the energy consumption data from different sectors and carbon emission factors from different energy. Each year's data of energy consumption from various industries are derived from corresponding year's China Energy Statistical Yearbook [33] and consolidate some sectors to meet our need. Considering the energy statistics caliber of China Energy Statistical Yearbook and the availability of energy carbon emission factors, we select coal, coke, crude oil, gasoline, kerosene, diesel oil, fuel oil, natural gas, and electricity, these nine kinds of energy. Every kind of energy's carbon emission factors is calculated in accordance with the low calorific capacity of energy sources released by the general principles of the comprehensive energy consumption in China and carbon content of unit calorific value and carbon oxidation rate coefficient from provincial greenhouse gas inventory compilation guide. And the carbon emission factor of electricity is the average carbon emissions of Chinese regional power grid in 2005. Specific data are shown in Table 2.

\section{Results and Analysis}

3.1. The Changes of Total Indirect Carbon Emissions from Residential Consumption. In order to understand more deeply the characteristics and structure of carbon emissions from residential consumption, this paper will first analyze the total indirect carbon emissions from residential consumption. By comparing it with the total carbon emissions from national energy consumption, we will have a deep understanding of the total carbon emissions from Chinese residential consumption. The specific results are shown in Figure 1.

From Figure 1, we can see that the total indirect carbon emissions from residential consumption in China increase year by year from 2002 to 2011. It increases by $91.65 \%$ from 642.215 million tons in 2002 to 1230.813 million tons in 2011, which shows that we should pay enough attention to the carbon emissions from residential consumption that has become one of the main sources of carbon emissions in China. From the figure, we can also learn that the national total carbon emissions from energy consumption increase by $148.86 \%$ from 1597.232 million tons in 2002 to 3974.943 million tons in 2011. So, we can know that the situation of carbon emissions is becoming worse and worse in China for nearly decade 


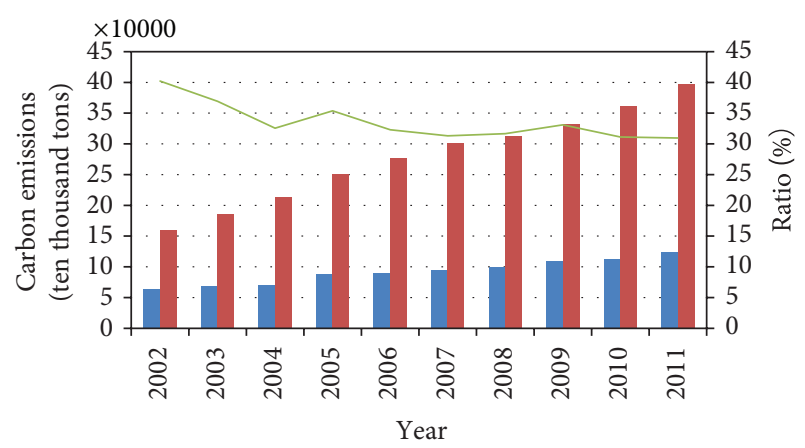

The total carbon emissions from residential consumption

The total carbon emissions from national energy consumption

_ The ratio of carbon emissions caused by residential consumption in national energy consumption

FIGURE 1: The changes of the total indirect carbon emissions from residential consumption in China and the ratio of it in the national carbon emissions.

and the energy consumption increase with time. In order to achieve sustainable development of economy, we should pay more attention to the carbon emissions and prevent it from further deterioration. The ratio of the total carbon emissions from residential consumption in the national total carbon emissions from energy consumption tells us that it declines by years from 2002 to 2004 and begins to recover in 2005 and after that it decreases again and gradually levels off in the last. This shows that though the total carbon emissions from residential consumption increase, their increasing ratio is lower than that of national total carbon emissions between 2002 and 2004. In recent years, this ratio becomes stable, and the total carbon emissions from residential consumption account for about $30 \%$ of the national total carbon emissions from energy consumption.

In conclusion, though the total carbon emissions from residential consumption increase year by year in China, their increasing ratio is lower than that of the national total carbon emissions. This demonstrates that the carbon emissions from residential consumption in China are not the main reason for sharply increase of Chinese total carbon emissions from energy consumption by years. But their proportion, which account for about $30 \%$, also cannot be overlooked. In the nearly decade, the increase of the total carbon emissions from residential consumption cannot be separated with the increase of population, the improvement of residents' consumption, and the acceleration of urbanization in China. Therefore, we should try to guide and change people's consuming behavior, and advocate healthy and green lifestyle to pay more attention to saving energy and control carbon emissions in respect to people's behavior. Besides, we should take environment into consideration when speeding up urbanization and control the speed of economic development within the capacity of environment. We should change residents' energy consumption structure and encourage residents to use clean energy with low carbon level. Only in this way will it be possible to reach the goal of inhibiting the increase of total carbon emissions.
3.2. The Changes of Urban and Rural Residents' Consumption Indirect Carbon Emissions. From the above analysis, we know that the total indirect carbon emissions from residential consumption increase by years in China, and its proportion accounts for about $30 \%$ of the national total carbon emissions from energy consumption. So, it is necessary to compare the carbon emissions from rural residents' consumption and urban residents' consumption to find their fluctuation characteristics and differences in recent ten years and put forward the corresponding measures and suggestions. Next, we are going to analyze the changes of the total indirect carbon emissions from urban and rural residents' consumption (as shown in Figure 2) and the changes of the ratio of carbon emissions from urban and rural residents' consumption in the total carbon emissions from residential consumption (as shown in Figure 3).

From Figure 2, we know that the total indirect carbon emissions from urban and rural residents' consumption increase year by year. And the total indirect carbon emissions from rural residents' consumption increase by $44.25 \%$ from 177.132 million tons in 2002 to 255.511 million tons in 2011; the total indirect carbon emissions from urban residents' consumption increase by $109.7 \%$ from 465.083 million tons in 2002 to 975.302 million tons in 2011. It can be seen that the indirect carbon emissions from urban residents' consumption are the main part of carbon emissions from residential consumption, and its annual growth ratio is higher than that of rural residents. In addition, from Figure 2, we can also know that the gap between indirect carbon emissions caused by rural and urban residents' consumption is wider and wider with time, which indicates that the increase of carbon emissions from urban residents' consumption is greater than that in rural areas. So, we should pay more attention to the carbon emissions from urban residents' consumption. From Figure 3, we can see that the proportion of carbon emissions from rural residents' consumption in the total carbon emissions induced by residential consumption declines by years in the nearly decade, while the carbon emissions from the urban residents' consumption is just the opposite, showing an increasing trend and the proportion it accounts for the total carbon emissions from residential consumption has reached more than 79\%. It also illustrates that the indirect carbon emissions from urban residents' consumption is the main part of carbon emissions from residential consumption.

In conclusion, the increase of carbon emissions from urban residents' consumption is the main reason for increasing of the total carbon emissions from residential consumption. It is inseparable from the increase of urban population and the improvement of urban residents' per capita income. With the improvement of Chinese urban residents' consumption level, consumers prefer to buy more goods. Together with the increase of urban population, there is no doubt that it will increase the indirect carbon emissions in urban area. So, we should pay more attention to the urban residents' consumption, guide people to change their consuming structure and attitude step by step, and encourage them to utilize energy with low carbon content (e.g., use more public transportation instead of private cars). We should raise 


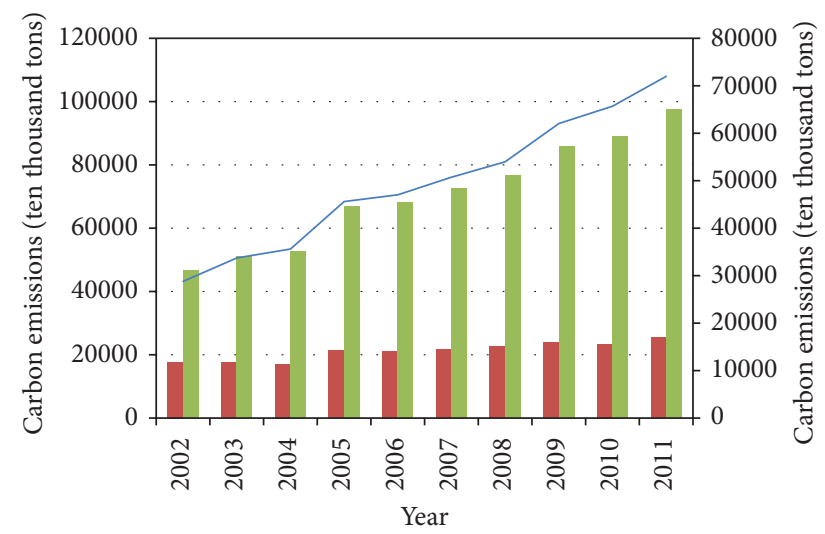

Indirect carbon emissions from rural residenetial consumption
Indirect carbon emissions from urban residential consumption
The gap between them

FIGURE 2: The changes of the total indirect carbon emissions from urban and rural residents' consumption and the fluctuation of the gap between them.

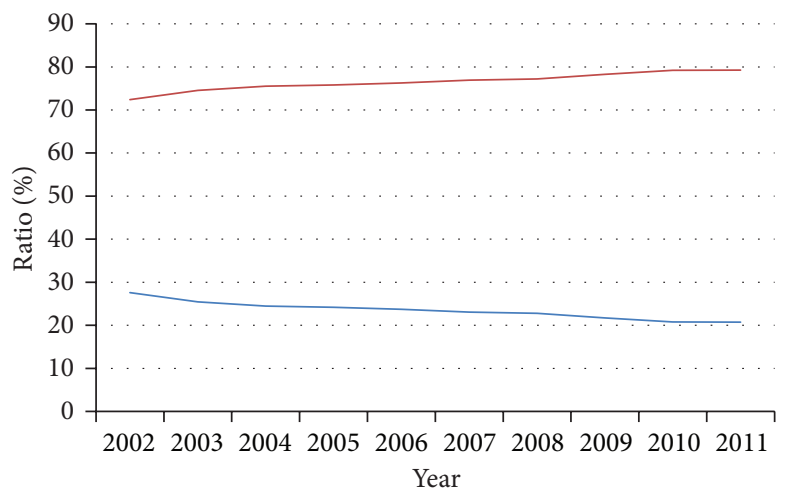

- The ratio of carbon emissions from rural residents consumption in the total carbon emissions from residential consumption

- The ratio of carbon emissions from urban residents consumption in the total carbon emissions from residential consumption

FIGURE 3: The changes of the ratio of carbon emissions from urban and rural residents' consumption in the total carbon emissions from residential consumption.

people's awareness of low-carbon lifestyle and lead them to a path of low-carbon sustainable development.

\subsection{The Changes of Per Capita Indirect Carbon Emissions in} Urban and Rural Areas. The above part mainly analyzes the changes of carbon emissions caused by residential consumption from the perspective of total carbon emissions and proportion. But, the population is also an important factor that influences carbon emissions. So, we will observe the changes of carbon emissions caused by residential consumption from the point of per capita carbon emissions in urban and rural areas, and the results are shown in Figure 4.

From Figure 4, we can know that the per capita indirect carbon emissions in urban and rural areas increase year by year. Among them, the per capita indirect carbon emissions

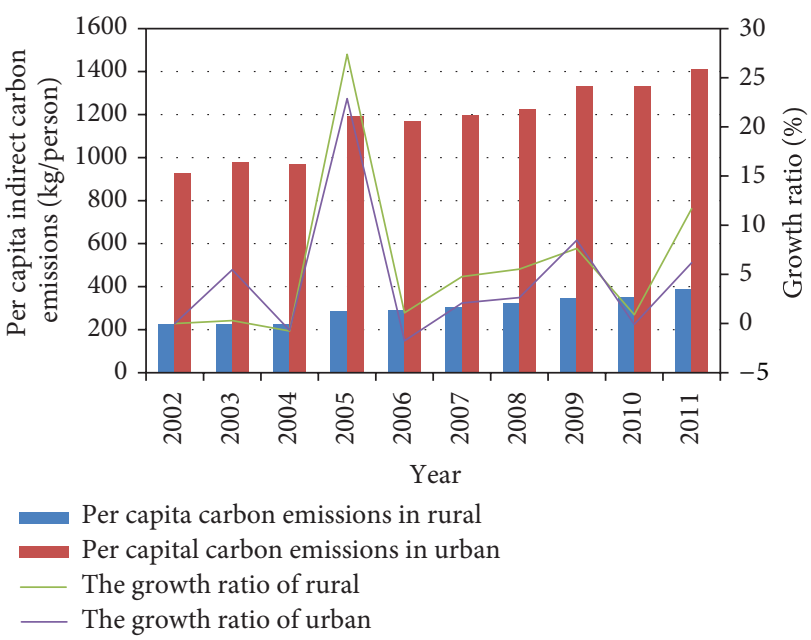

FIGURE 4: The changes of per capita indirect carbon emissions in urban and rural areas and annual growth ratio.

from rural residents' consumption increase by $71.91 \%$ from $226.4 \mathrm{~kg}$ in 2002 to $389.2 \mathrm{~kg}$ in 2011; the per capita indirect carbon emissions from urban residents' consumption increase by $52.44 \%$ from $926.2 \mathrm{~kg}$ in 2002 to $1411.9 \mathrm{~kg}$ in 2011 . And the per capita indirect carbon emissions from urban residents' consumption is nearly 3 to 4 times than that of rural area, but there is a downward trend. From the picture, we can also learn that the annual growth ratio of per capita carbon emissions in the country is higher than that in the town after 2004. Though the per capita carbon emissions in rural area are far less than those in urban area, their annual growth ratio is higher. That is to say, the carbon emissions from rural residents' consumption have a strong growth trend in the future.

In conclusion, we learn that the per capita carbon emissions in urban area are nearly 3 to 4 times higher than those in rural area when observing carbon emissions from the per capita carbon emissions in urban and rural areas. But their annual growth ratio of per capita carbon emissions is less after 2004. This may be because the cardinal number of carbon emissions from urban residents' consumption has already been very large, while the cardinal number of carbon emissions from rural residents' consumption is relatively small. When adding the same amount of carbon emissions, the annual growth ratio of per capita carbon emissions in rural area is much higher. It also illustrates that the carbon emissions from rural residents' consumption have a strong growth trend in the future. Therefore, we cannot ignore the growth of carbon emissions caused by rural residential consumption because its small proportion accounts for the total carbon emissions led by residential consumption. We should control carbon emissions from urban residential consumption as well as that generated by rural residents' consumption. At present, we must control the carbon emissions caused by urban residents' consumption for its per capita carbon emissions are 3 to 4 times higher than that in rural areas. Moreover, carbon emissions caused by rural residents' consumption are going to have a strong 
TABLE 3: Carbon emissions from rural residents' consumption by sectors (unit: $10^{10}$ tons).

\begin{tabular}{|c|c|c|c|c|c|c|c|c|c|c|}
\hline & \multicolumn{2}{|c|}{2002} & \multicolumn{2}{|c|}{2003} & \multicolumn{2}{|c|}{2004} & \multicolumn{2}{|c|}{2005} & \multicolumn{2}{|c|}{2006} \\
\hline & $\begin{array}{c}\text { Carbon } \\
\text { emissions }\end{array}$ & Ratio & $\begin{array}{c}\text { Carbon } \\
\text { emissions }\end{array}$ & Ratio & $\begin{array}{c}\text { Carbon } \\
\text { emissions }\end{array}$ & Ratio & $\begin{array}{c}\text { Carbon } \\
\text { emissions }\end{array}$ & Ratio & $\begin{array}{c}\text { Carbon } \\
\text { emissions }\end{array}$ & Ratio \\
\hline 1 & 39.02 & $22.03 \%$ & 42.72 & $24.48 \%$ & 43.32 & $25.39 \%$ & 36.34 & $16.98 \%$ & 27.91 & $3.14 \%$ \\
\hline 6 & 24.36 & $13.75 \%$ & 24.82 & $14.23 \%$ & 24.39 & $14.30 \%$ & 29.75 & $13.90 \%$ & 31.33 & $14.76 \%$ \\
\hline 8 & 4.25 & $2.40 \%$ & 3.61 & $2.07 \%$ & 3.21 & $1.88 \%$ & 6.2 & $2.90 \%$ & 9.26 & $4.36 \%$ \\
\hline 12 & 12.5 & $7.06 \%$ & 10.1 & $5.79 \%$ & 8.12 & $4.76 \%$ & 14.06 & $6.57 \%$ & 11.53 & $5.43 \%$ \\
\hline 17 & 3.57 & $2.01 \%$ & 2.63 & $1.51 \%$ & 2.37 & $1.39 \%$ & 8.82 & $4.12 \%$ & 6.6 & $3.11 \%$ \\
\hline 18 & 3.19 & $1.80 \%$ & 2.47 & $1.42 \%$ & 2.09 & $1.22 \%$ & 7.95 & $3.71 \%$ & 6.52 & $3.07 \%$ \\
\hline 22 & 14.08 & $7.95 \%$ & 14.9 & $8.54 \%$ & 12.94 & $7.58 \%$ & 10.97 & $5.13 \%$ & 25.47 & $12.00 \%$ \\
\hline 26 & 8.37 & $4.73 \%$ & 7.55 & $4.33 \%$ & 7.09 & $4.15 \%$ & 16.24 & $7.59 \%$ & 8.17 & $3.85 \%$ \\
\hline 27 & 6.97 & $3.93 \%$ & 6.06 & $3.47 \%$ & 5.69 & $3.33 \%$ & 6.04 & $2.82 \%$ & 9.44 & $4.45 \%$ \\
\hline 28 & 4.91 & $2.77 \%$ & 5.17 & $2.96 \%$ & 5.39 & $3.16 \%$ & 6.39 & $2.99 \%$ & 9.49 & $4.47 \%$ \\
\hline 30 & 11.1 & $6.27 \%$ & 11.4 & $6.54 \%$ & 12.3 & $7.21 \%$ & 8.82 & $4.12 \%$ & 8.17 & $3.85 \%$ \\
\hline 31 & 19.79 & $11.17 \%$ & 21.37 & $12.24 \%$ & 23.26 & $13.63 \%$ & 31.61 & $14.77 \%$ & 32.17 & $15.15 \%$ \\
\hline \multirow[t]{3}{*}{ Total } & 152.11 & $85.87 \%$ & 152.82 & $87.57 \%$ & 150.16 & $88.02 \%$ & 183.18 & $85.61 \%$ & 186.06 & $87.65 \%$ \\
\hline & \multicolumn{2}{|c|}{2007} & \multicolumn{2}{|c|}{2008} & \multicolumn{2}{|c|}{2009} & \multicolumn{2}{|c|}{2010} & \multicolumn{2}{|c|}{2011} \\
\hline & $\begin{array}{c}\text { Carbon } \\
\text { emissions }\end{array}$ & Ratio & $\begin{array}{c}\text { Carbon } \\
\text { emissions }\end{array}$ & Ratio & $\begin{array}{c}\text { Carbon } \\
\text { emissions }\end{array}$ & Ratio & $\begin{array}{c}\text { Carbon } \\
\text { emissions }\end{array}$ & Ratio & $\begin{array}{c}\text { Carbon } \\
\text { emissions }\end{array}$ & Ratio \\
\hline 1 & 28.49 & $13.11 \%$ & 28.24 & $12.50 \%$ & 28.58 & $12.01 \%$ & 25.64 & $10.97 \%$ & 27.82 & $10.89 \%$ \\
\hline 6 & 32.03 & $14.74 \%$ & 34.2 & $15.14 \%$ & 36.45 & $15.31 \%$ & 46.07 & $19.70 \%$ & 50.2 & $19.65 \%$ \\
\hline 8 & 9.91 & $4.56 \%$ & 10.9 & $4.84 \%$ & 12.88 & $5.41 \%$ & 12.61 & $5.39 \%$ & 13.58 & $5.31 \%$ \\
\hline 12 & 12.28 & $5.65 \%$ & 13.31 & $5.89 \%$ & 18 & $7.56 \%$ & 12.27 & $5.25 \%$ & 13.67 & $5.35 \%$ \\
\hline 17 & 7.02 & $3.23 \%$ & 6.7 & $2.97 \%$ & 5.69 & $2.39 \%$ & 8.49 & $3.63 \%$ & 9.47 & $3.70 \%$ \\
\hline 18 & 7.1 & $3.27 \%$ & 7.29 & $3.23 \%$ & 7.28 & $3.06 \%$ & 9.64 & $4.12 \%$ & 10.84 & $4.24 \%$ \\
\hline 22 & 25.75 & $11.85 \%$ & 27.33 & $12.10 \%$ & 27 & $11.34 \%$ & 24.42 & $10.44 \%$ & 26.98 & $10.56 \%$ \\
\hline 26 & 8.16 & $3.76 \%$ & 8.59 & $3.80 \%$ & 9.88 & $4.15 \%$ & 7.81 & $3.34 \%$ & 8.55 & $3.35 \%$ \\
\hline 27 & 12.08 & $5.56 \%$ & 12.38 & $5.48 \%$ & 12.29 & $5.16 \%$ & 8.88 & $3.80 \%$ & 9.91 & $3.88 \%$ \\
\hline 28 & 9.19 & $4.23 \%$ & 9.42 & $4.17 \%$ & 9.65 & $4.05 \%$ & 8.09 & $3.46 \%$ & 8.72 & $3.41 \%$ \\
\hline 30 & 7.3 & $3.36 \%$ & 6.73 & $2.98 \%$ & 6.3 & $2.65 \%$ & 9.03 & $3.86 \%$ & 10.01 & $3.92 \%$ \\
\hline 31 & 32.17 & $14.80 \%$ & 33.03 & $14.62 \%$ & 31.56 & $13.26 \%$ & 32.73 & $14.00 \%$ & 34.83 & $13.63 \%$ \\
\hline Total & 191.5 & $88.10 \%$ & 198.12 & $87.71 \%$ & 205.56 & $86.34 \%$ & 205.69 & $87.95 \%$ & 224.57 & $87.89 \%$ \\
\hline
\end{tabular}

Notes: the table only lists 12 departments, of which the carbon emissions are relatively high. The first column below each year is the amount of carbon emissions, and the second column is the ratio of carbon emissions produced by relevant department in the total carbon emissions from rural residential consumption.

momentum, so we should do a good job of control in advance (e.g., encourage rural people to use methane, solar energy, and so on).

3.4. Analysis of Carbon Emissions from Residents' Consumption by Sectors. In order to know more clearly about carbon emissions caused by residents' consumption and have more in-depth understanding about distribution of carbon emissions induced by resident consumption structure, we are dividing carbon emissions caused by residents' consumption in terms of industry. As shown in Table 3, we choose 12 sectors, in which the indirect carbon emissions are relatively high. They are farming, forestry, animal husbandry, fishery, and water conservancy; manufacture of foods and tobacco; manufacture of wearing apparel, leather, feather, and related products; manufacture of chemical products; manufacture of transport equipment; manufacture of electrical machinery and equipment; production and distribution of electric power and heat power; transport and storage postal service; wholesale and retail trade; hotel and restaurants; real estate; other services. The total carbon emissions of these sectors led by residents' consumption take up more than $85 \%$ of the total residents' consumption carbon emission. So, these are main departments that produce carbon emissions from residents' consumption. Through the research on them, we can learn well about the structure of the source of carbon emissions caused by residents' consumption and make targeted control.

Table 3 shows the carbon emissions from rural residents' consumption by sectors. We learn that the total carbon emissions led by rural residents' consumption of the 12 departments are increasing by years, from $1.52 \times 10^{12}$ tons in 2002 to $2.25 \times 10^{12}$ tons in 2011. Among them, the total carbon emissions and proportion of manufacture of foods and tobacco show the trend of increasing year by year, 
from $2.44 \times 10^{11}$ tons in 2002 to $5.02 \times 10^{11}$ tons, and the proportion increases from $13.75 \%$ to $19.65 \%$. The total carbon emissions and proportion of manufacture of wearing apparel, leather, feather, and related products; manufacture of transport equipment; manufacture of electrical machinery and equipment; production and distribution of electric power and heat power and hotel and restaurants fluctuate with years but increase as a whole. The total carbon emissions of manufacture of wearing apparel, leather, feather, and related products increase from $4.25 \times 10^{10}$ tons in 2002 to $1.36 \times 10^{11}$ tons in 2011, and the proportion increases from $2.4 \%$ to $5.31 \%$. The total carbon emissions of manufacture of transport equipment rise from $3.57 \times 10^{10}$ tons in 2002 to $9.47 \times 10^{10}$ tons in 2011, and the proportion rises from $2.01 \%$ to $3.70 \%$. The total carbon emissions of manufacture of electrical machinery and equipment increases from $3.19 \times 10^{10}$ tons in 2002 to $1.08 \times 10^{11}$ tons in 2011, and the proportion increases from $1.8 \%$ to $4.24 \%$. Meanwhile, $1.41 \times 10^{11}$ tons carbon emissions of production and distribution of electric power and heat power in 2002 goes up to $2.70 \times 10^{11}$ tons in 2011 with a fluctuated proportion from $7.95 \%$ to $10.56 \%$. The total carbon emissions of hotel and restaurants fluctuate from $4.91 \times$ $10^{10}$ tons in 2002 and finally goes up to $8.72 \times 10^{10}$ tons in 2011, and the proportion rises from $2.77 \%$ to $3.41 \%$. The total carbon emission caused by rural residents' consumption in the manufacture of chemical products; transport and storage postal service; wholesale and retail trade; real estate changes little between 2002 and 2011. While, the carbon emissions of farming, forestry, animal husbandry, fishery, and water conservancy decline from $3.9 \times 10^{11}$ tons in 2002 to $2.78 \times$ $10^{11}$ tons in 2011, and the proportion declines from $22.03 \%$ to $10.89 \%$. That is to say, with the development of people's life standard, the structure of rural residents' consumption changes a lot with lower consumption of direct agricultural products and more attention to quality of life. Being inclined to food, tobacco and clothes, the rural residents' consumption makes a contribution to carbon emissions of these industries.

Table 4 shows the carbon emissions from urban residents' consumption by sectors. We learn that the total carbon emissions led by urban residents' consumption of the 12 departments are constantly increasing by years, rising from $3.76 \times 10^{12}$ tons in 2002 to $7.87 \times 10^{12}$ tons in 2011 . Among them, the total carbon emissions of manufacture of foods and tobacco and other services tend to increase year by year. The former increases from $4.58 \times 10^{11}$ tons in 2002 to $1.31 \times$ $10^{12}$ tons in 2011, and the proportion increases from $9.85 \%$ to $13.45 \%$, while the latter increases from $7.93 \times 10^{11}$ tons in 2002 to $1.88 \times 10^{12}$ tons in 2011 with an increased proportion from $17.06 \%$ to $19.31 \%$. The total carbon emissions and proportion of manufacture of wearing apparel, leather, feather, and related products; manufacture of transport equipment; manufacture of electrical machinery and equipment and real estate fluctuate with years but increase as a whole. Their carbon emissions are, respectively, from $2.28 \times 10^{11}$ tons, $7.78 \times$ $10^{10}$ tons, $1.39 \times 10^{11}$ tons, $1.27 \times 10^{11}$ tons in 2002 to $5.81 \times$ $10^{11}$ tons, $5.08 \times 10^{11}$ tons, $4.03 \times 10^{11}$ tons, $4.46 \times 10^{11}$ tons in 2011 and the corresponding proportions are from $4.89 \%$, $1.61 \%, 2.99 \%$, and $2.73 \%$ to $5.96 \%, 5.21 \%$, $4.14 \%$, and $4.57 \%$.
In addition, the total carbon emissions of manufacture of chemical; production and distribution of electric power and heat power; transport and storage postal service; wholesale and retail trade; hotel and restaurants present the trend of increase as a whole but decline in terms of proportion because of small modest increase. The carbon emissions of farming, forestry, animal husbandry, fishery, and water conservancy decline with years from $4.38 \times 10^{11}$ tons in 2002 to $3.13 \times$ $10^{11}$ tons in 2011, and the proportion declines from $9.41 \%$ to $3.20 \%$. The structure of urban residents' consumption is changing gradually, which stimulates the fluctuation of carbon emissions in different industries. From the above data, we can learn that urban residents consume more products of food manufacturing and tobacco processing and less direct agricultural products. Since the market of service has been opened gradually, the carbon emission is also increasing.

From the perspective of different industries, the total carbon emissions caused by urban and rural residents' consumption of products of primary industry declines by years. That is to say, with the development of people's life standard, the purchase of direct agricultural products is decreasing. The indirect total carbon emissions caused by rural residents' consumption of products of secondary industry increases by years, as well as the proportion. However, the indirect total carbon emissions caused by consumption of products of tertiary industry fluctuate slightly, and the proportion changes little. Therefore, we conclude that rural residents increase their demand for products of secondary industry but little change in demand for products of tertiary industry. The urban residents' consumption of products of secondary industry increases as rural residents but have a less range. While the carbon emissions caused by their demand for products of tertiary industry increases obviously, which illustrate that the trend of consumption of urban residents is transferring from secondary industry to tertiary industry. In conclusion, urban residents tend to tertiary industry, while rural residents rely mainly on secondary industry. As we all known, secondary industry is an energy-intensive industry, which is one of the reasons why the increase rate of average carbon emissions of rural residents' consumption is higher than that of urban residents' consumption. Therefore, we should guide residents' consumption toward the tertiary industry.

According to above analysis, the carbon emissions caused by rural and urban residents' consumption of direct agricultural decline gradually but increase by consumption of manufacture of foods and tobacco. So, we should take proper steps to control the carbon emissions of manufacture of foods and tobacco. For example, we can transform the manufacturing technique, eliminate obsolete equipment through technological innovation, improve the energy utilization rate of food equipment or use clean energy. Furthermore, we should advocate healthy lifestyle to reduce the consumption of tobacco. The secondary industry is an energy-intensive industry and both carbon emissions caused by rural and urban residents' consumption of products of secondary industry increase, so we should guide residents' consumption toward tertiary industry reasonably, such as offering 
TABLE 4: Carbon emissions from urban residents' consumption by sectors (unit: $10^{10}$ tons).

\begin{tabular}{|c|c|c|c|c|c|c|c|c|c|c|}
\hline & \multicolumn{2}{|c|}{2002} & \multicolumn{2}{|c|}{2003} & \multicolumn{2}{|c|}{2004} & \multicolumn{2}{|c|}{2005} & \multicolumn{2}{|c|}{2006} \\
\hline & $\begin{array}{c}\text { Carbon } \\
\text { emissions }\end{array}$ & Ratio & $\begin{array}{c}\text { Carbon } \\
\text { emissions }\end{array}$ & Ratio & $\begin{array}{c}\text { Carbon } \\
\text { emissions }\end{array}$ & Ratio & $\begin{array}{c}\text { Carbon } \\
\text { emissions }\end{array}$ & Ratio & $\begin{array}{c}\text { Carbon } \\
\text { emissions }\end{array}$ & Ratio \\
\hline 1 & 43.76 & $9.41 \%$ & 54.41 & $10.63 \%$ & 58.82 & $11.17 \%$ & 39.21 & $5.85 \%$ & 31.11 & $4.56 \%$ \\
\hline 6 & 45.82 & $9.85 \%$ & 53.05 & $10.37 \%$ & 55.58 & $10.55 \%$ & 59.8 & $8.92 \%$ & 83.9 & $12.29 \%$ \\
\hline 8 & 22.76 & $4.89 \%$ & 21.96 & $4.29 \%$ & 20.82 & $3.95 \%$ & 38.94 & $5.81 \%$ & 40.72 & $5.97 \%$ \\
\hline 12 & 23.82 & $5.12 \%$ & 21.87 & $4.27 \%$ & 18.73 & $3.56 \%$ & 28.22 & $4.21 \%$ & 31.32 & $4.59 \%$ \\
\hline 17 & 7.78 & $1.67 \%$ & 6.52 & $1.27 \%$ & 6.26 & $1.19 \%$ & 11.86 & $1.77 \%$ & 24.3 & $3.56 \%$ \\
\hline 18 & 13.91 & $2.99 \%$ & 12.25 & $2.39 \%$ & 11.03 & $2.10 \%$ & 32.62 & $4.87 \%$ & 22.01 & $3.23 \%$ \\
\hline 22 & 62.51 & $13.44 \%$ & 75.12 & $14.68 \%$ & 69.53 & $13.20 \%$ & 62.83 & $9.38 \%$ & 88.86 & $13.02 \%$ \\
\hline 26 & 23.28 & $5.01 \%$ & 23.85 & $4.66 \%$ & 23.86 & $4.53 \%$ & 52.95 & $7.90 \%$ & 25.47 & $3.73 \%$ \\
\hline 27 & 18.34 & $3.94 \%$ & 18.12 & $3.54 \%$ & 18.13 & $3.44 \%$ & 16.37 & $2.44 \%$ & 25.01 & $3.66 \%$ \\
\hline 28 & 22.38 & $4.81 \%$ & 26.76 & $5.23 \%$ & 29.76 & $5.65 \%$ & 35.89 & $5.36 \%$ & 31.22 & $4.57 \%$ \\
\hline 30 & 12.69 & $2.73 \%$ & 14.81 & $2.89 \%$ & 17.03 & $3.23 \%$ & 15.31 & $2.29 \%$ & 18.32 & $2.68 \%$ \\
\hline 31 & 79.34 & $17.06 \%$ & 97.28 & $19.01 \%$ & 112.91 & $21.44 \%$ & 139.46 & $20.81 \%$ & 137.4 & $20.13 \%$ \\
\hline \multirow[t]{3}{*}{ Total } & 376.39 & $80.93 \%$ & 425.99 & $83.25 \%$ & 442.47 & $84.02 \%$ & 533.45 & $79.61 \%$ & 559.65 & $81.99 \%$ \\
\hline & \multicolumn{2}{|c|}{2007} & \multicolumn{2}{|c|}{2008} & \multicolumn{2}{|c|}{2009} & \multicolumn{2}{|c|}{2010} & \multicolumn{2}{|c|}{2011} \\
\hline & $\begin{array}{c}\text { Carbon } \\
\text { emissions }\end{array}$ & Ratio & $\begin{array}{c}\text { Carbon } \\
\text { emissions }\end{array}$ & Ratio & $\begin{array}{c}\text { Carbon } \\
\text { emissions }\end{array}$ & Ratio & $\begin{array}{c}\text { Carbon } \\
\text { emissions }\end{array}$ & Ratio & $\begin{array}{c}\text { Carbon } \\
\text { emissions }\end{array}$ & Ratio \\
\hline 1 & 33.11 & $4.57 \%$ & 33.32 & $4.35 \%$ & 36.26 & $4.22 \%$ & 28.7 & $3.22 \%$ & 31.25 & $3.20 \%$ \\
\hline 6 & 89.42 & $12.34 \%$ & 96.89 & $12.66 \%$ & 111.05 & $12.93 \%$ & 119.94 & $13.47 \%$ & 131.17 & $13.45 \%$ \\
\hline 8 & 45.43 & $6.27 \%$ & 50.84 & $6.64 \%$ & 64.45 & $7.51 \%$ & 53.75 & $6.04 \%$ & 58.11 & $5.96 \%$ \\
\hline 12 & 34.77 & $4.80 \%$ & 38.26 & $5.00 \%$ & 55.63 & $6.48 \%$ & 40.03 & $4.49 \%$ & 44.73 & $4.59 \%$ \\
\hline 17 & 26.96 & $3.72 \%$ & 26.11 & $3.41 \%$ & 23.82 & $2.77 \%$ & 45.42 & $5.10 \%$ & 50.82 & $5.21 \%$ \\
\hline 18 & 25.02 & $3.45 \%$ & 26.05 & $3.40 \%$ & 28 & $3.26 \%$ & 35.73 & $4.01 \%$ & 40.33 & $4.14 \%$ \\
\hline 22 & 93.64 & $12.92 \%$ & 100.88 & $13.17 \%$ & 107.18 & $12.48 \%$ & 89.74 & $10.08 \%$ & 99.51 & $10.20 \%$ \\
\hline 26 & 26.52 & $3.66 \%$ & 28.31 & $3.70 \%$ & 35.02 & $4.08 \%$ & 32.34 & $3.63 \%$ & 35.55 & $3.65 \%$ \\
\hline 27 & 33.35 & $4.60 \%$ & 34.7 & $4.53 \%$ & 37.02 & $4.31 \%$ & 26.03 & $2.92 \%$ & 29.16 & $2.99 \%$ \\
\hline 28 & 31.55 & $4.35 \%$ & 32.79 & $4.28 \%$ & 36.14 & $4.21 \%$ & 31.02 & $3.48 \%$ & 33.55 & $3.44 \%$ \\
\hline 30 & 17.06 & $2.35 \%$ & 15.95 & $2.08 \%$ & 16.07 & $1.87 \%$ & 40.11 & $4.50 \%$ & 44.6 & $4.57 \%$ \\
\hline 31 & 143.25 & $19.76 \%$ & 149.27 & $19.50 \%$ & 153.37 & $17.86 \%$ & 176.33 & $19.80 \%$ & 188.33 & $19.31 \%$ \\
\hline Total & 600.06 & $82.79 \%$ & 633.37 & $82.72 \%$ & 704 & $82.00 \%$ & 719.16 & $80.74 \%$ & 787.14 & $80.71 \%$ \\
\hline
\end{tabular}

Notes: The table only lists 12 departments, of which the carbon emissions are relatively high. The first column below each year is the amount of carbon emissions, and the second column is the ratio of carbon emissions produced by relevant department in the total carbon emissions from urban residential consumption.

preferential policies for consumption of products of tertiary industry to control purchases of secondary industry. In this way, not only can we insure the development of economy but also reduce the carbon emissions.

\section{Conclusion and Policy Suggestion}

This paper uses RAS method first to deduce the inputoutput table of the vacant years between 2002 and 2011 and obtain the successive time-series input-output table. Then, we use input-output method to calculate indirect carbon emissions caused by urban and rural residents' consumption between 2002 and 2011 to obtain some conclusions. (1) From 2002 to 2011, the indirect carbon emissions caused by urban and rural residents' consumption increase gradually, but the percentage it accounts for declines by years. That is to say, though the total indirect carbon emission caused by residents' consumption increases every year, the increase range is less than that of national carbon emissions. (2) By comparing the indirect carbon emissions, we realize that the carbon emissions caused by urban residents' consumption is the main component of the whole carbon emissions, and the gap between carbon emissions caused by urban residents' consumption and rural residents' consumption is widen. (3) The average indirect carbon emissions rise by years and the increment of urban carbon emissions is larger than that of rural carbon emissions. But the proportion of growth of the urban carbon emissions is less than that of rural carbon emissions since 2004, which shows that the carbon emissions caused by rural residents' consumption have a strong growth trend and we should control carbon emissions caused by urban residents' consumption as well as the carbon emissions caused by rural residents' consumption. 
(4) We discover that the carbon emissions caused by urban and rural residents' consumption of direct agricultural products decrease, while carbon emissions produced by consuming food and tobacco increase. In terms of different industries, we find that the carbon emissions caused by urban and rural residents' consumption of products of primary industry decrease with years, and the urban residents' demand for goods of secondary industry is transferring toward the goods of tertiary industry, but the rural residents' demand mainly focus on products of secondary industry, which will shift to tertiary industry in the future.

With the increase of the population, acceleration of the urbanization, and development of people's living standard of China, the carbon emissions caused by residents' consumption is rising with each passing year. Therefore, it is necessary to take proper measures to control carbon emissions caused by residents' consumption. We propose the following suggestions in accordance with our research. (1) With the development of China's economy and level of living, people tend to consume more energy and products. So, we should try to guide and change people's consuming behavior to use more clean energy and advocate healthy and green lifestyle to pay more attention to saving energy and control carbon emissions in respect to people's behavior. Besides, we should take environment into consideration when speeding up urbanization and control the speed of economy within the capacity of environment. (2) People's energy consuming structure must be changed and clean energy with low carbon level must be encouraged to use, especially for rural residents whose demand for cheap products with high carbon level are more due to the low standard of living. We can see much more space to optimize. (3) At present, we must control the carbon emissions caused by urban residents' consumption, guide people to change their consuming structure and attitude step by step, and encourage them to utilize energy with low carbon content (e.g., use more public transportation instead of private cars). We should raise people's awareness of low-carbon lifestyle and lead them to a path of low-carbon sustainable development. Moreover, carbon emissions caused by rural residents' consumption are going to have a strong momentum, so we should do a good job of control in advance (e.g., encourage rural people to use methane, solar energy, and so on). (4) We should take proper measures to control carbon emissions of food manufacturing and tobacco processing industry, such as transforming the manufacturing technique, eliminating obsolete equipment through technological innovation, improving the energy utilization rate of food equipment or using clean energy and so on. Furthermore, we also should advocate healthy lifestyle to reduce the consumption of tobacco. (5) Because most of products of secondary industry are energy-intensive, we should start with improving residents' consuming structure and guide them to use more products with low carbon level to encourage them to purchase more products of tertiary industry and service and less products of secondary industry.

In future, input-output method will be used to find more information on carbon emissions caused by households' consumption, government expenditures, fixed capital formation, and import and export, and so forth from the perspective of final demands. In addition, we should do more researches about the development, implementation, and evaluation of low-carbon policies. Because most studies are just staying in the phase of phenomenon analysis, they lack specific policy implementation and evaluation system. Moreover, the residential consumption in this paper includes imported goods. But the carbon emissions of imported goods are produced in foreign countries. So, the future researches should remove the imported goods. The carbon emissions in this study are just produced by residential energy consumption, they do not include the carbon emissions generated during the production. Therefore, we should do more work to complete this in the future. Finally, applications of input-output table in this research are based on the assumption of a steady economic state during its compilation period. However, actual economic systems are dynamic. Future work should pay special attention to the simulation of dynamic systems.

\section{Conflict of Interests}

The authors declare that there is no conflict of interests regarding the publication of this paper.

\section{Acknowledgments}

This paper is financially supported by the National Natural Science Foundation of China (71103077), Science Foundation of Ministry of Education of China (10YJC630377), and Science Foundation of Postdoctoral of China (2012M512015).

\section{References}

[1] Y. Wang and M. Shi, " $\mathrm{CO}_{2}$ emission induced by urban household consumption in China," Chinese Journal of Population, Resources and Environment, vol. 7, no. 3, pp. 11-19, 2009.

[2] L.-C. Liu, G. Wu, J.-N. Wang, and Y.-M. Wei, "China's carbon emissions from urban and rural households during 1992-2007," Journal of Cleaner Production, vol. 19, no. 15, pp. 1754-1762, 2011.

[3] D. Zha, D. Zhou, and P. Zhou, "Driving forces of residential $\mathrm{CO}_{2}$ emissions in urban and rural China: an index decomposition analysis," Energy Policy, vol. 38, no. 7, pp. 3377-3383, 2010.

[4] J. L. Fan, H. Liao, Q.-M. Liang, H. Tatano, C.-F. Liu, and Y.M. Wei, "Residential carbon emission evolutions in urbanrural divided China: an end-use and behavior analysis," Applied Energy, vol. 101, pp. 323-332, 2013.

[5] L. Feng, T. Lin, and Q. Zhao, "Analysis of the dynamic characteristics of urban household energy use and carbon emissions in China," China Population, Resources and Environment, vol. 21, no. 5, pp. 93-100, 2011 (Chinese).

[6] C. Yao, C. Chen, and M. Li, "Analysis of rural residential energy consumption and corresponding carbon emissions in China," Energy Policy, vol. 41, pp. 445-450, 2012.

[7] W. Liu, G. Spaargaren, N. Heerink, P. J. Arthur M, and C. Wang, "Energy consumption practices of rural households in north China: basic characteristics and potential for low carbon development," Energy Policy, vol. 55, pp. 128-138, 2013.

[8] L. Liang, W. Wu, R. Lal, and Y. Guo, "Structural change and carbon emission of rural household energy consumption in Huantai, northern China," Renewable and Sustainable Energy Reviews, vol. 28, pp. 767-776, 2013. 
[9] Z.-H. Feng, L.-L. Zou, and Y.-M. Wei, “The impact of household consumption on energy use and $\mathrm{CO}_{2}$ emissions in China," Energy, vol. 36, no. 1, pp. 656-670, 2011.

[10] Y.-M. Wei, L.-C. Liu, Y. Fan, and G. Wu, “The impact of lifestyle on energy use and $\mathrm{CO}_{2}$ emission: an empirical analysis of China's residents," Energy Policy, vol. 35, no. 1, pp. 247-257, 2007.

[11] S. Bin and H. Dowlatabadi, "Consumer lifestyle approach to US energy use and the related $\mathrm{CO}_{2}$ emissions," Energy Policy, vol. 33, no. 2, pp. 197-208, 2005.

[12] M. Abu-Madi and M. Abu Rayyan, "Estimation of main greenhouse gases emission from household energy consumption in the West Bank, Palestine," Environmental Pollution, vol. 179, pp. 250-257, 2013.

[13] J. Munksgaard, K. A. Pedersen, and M. Wien, "Impact of household consumption on $\mathrm{CO}_{2}$ emissions," Energy Economics, vol. 22, no. 4, pp. 423-440, 2000.

[14] Q. Zhu, X. Peng, and K. Wu, "Calculation and decomposition of indirect carbon emissions from residential consumption in China based on the input-output model," Energy Policy, vol. 48, pp. 618-626, 2012.

[15] Y. Zhang, "Impact of urban and rural household consumption on carbon emissions in China," Economic Systems Research, vol. 25, no. 3, pp. 287-299, 2013.

[16] J. Fan, X. Guo, D. Marinova, Y. Wu, and D. Zhao, "Embedded carbon footprint of Chinese urban households: structure and changes," Journal of Cleaner Production, vol. 33, pp. 50-59, 2012.

[17] G. Q. Chen, S. Guo, L. Shao, J. S. Li, and C. Zhan-Ming, "Threescale input-output modeling for urban economy: carbon emission by Beijing 2007," Communications in Nonlinear Science and Numerical Simulation, vol. 18, no. 9, pp. 2493-2506, 2013.

[18] M. Cellura, S. Longo, and M. Mistretta, "Application of the structural decomposition analysis to assess the indirect energy consumption and air emission changes related to Italian households consumption," Renewable and Sustainable Energy Reviews, vol. 16, no. 2, pp. 1135-1145, 2012.

[19] D. Aparna and K. P. Saikat, " $\mathrm{CO}_{2}$ emissions from household consumption in India between 1993-94 and 2006-07: a decomposition analysis," Energy Economics, vol. 41, pp. 90-105, 2013.

[20] H.-C. Park and E. Heo, "The direct and indirect household energy requirements in the Republic of Korea from 1980 to 2000-an input-output analysis," Energy Policy, vol. 35, no. 5, pp. 2839-2851, 2007.

[21] C. Cohen, M. Lenzen, and R. Schaeffer, "Energy requirements of households in Brazil," Energy Policy, vol. 33, no. 4, pp. 555-562, 2005.

[22] R. W. Jackson and A. T. Murray, "Alternative input-output matrix updating formulations," Economic Systems Research, vol. 16, no. 2, pp. 135-148, 2004.

[23] M. L. Lahr and L. de Mesnard, "Biproportional techniques in input-output analysis: table updating and structural analysis," Economic Systems Research, vol. 16, no. 2, pp. 115-134, 2004.

[24] X. Chen and C. Yang, Input-Output Technology, Science Press of China.

[25] C. Huang, C. Peng, X. Chen, and F. Wen, "Dynamics analysis of a class of delayed economic model," Abstract and Applied Analysis, vol. 2013, Article ID 962738, 12 pages, 2013.

[26] A. Parikh, "Forecasts of input-output matrices using the RAS method," The Review of Economic and Statistics, vol. 61, pp. 477481, 1979.

[27] T. Mun-Heng, "Projecting the Leontief inverse directly by the RAS method," in Proceedings of the 12th International
Conference on Input-Output Techniques, New York, NY, USA, May 1998.

[28] M. H. Toh, "The RAS approach in updating input-output matrices: an instrumental variable interpretation and analysis of structural changes," Economic Systems Research, vol. 10, no. 1, pp. 63-78, 1998.

[29] T. Junius and J. Oosterhaven, "The solution of updating or regionalizing a matrix with both positive and negative entries," Economic Systems Research, vol. 15, no. 1, pp. 87-96, 2003.

[30] R. W. Jackson and A. T. Murray, "Alternative input-output matrix updating formulations," Economic Systems Research, vol. 16, no. 2, pp. 135-148, 2004.

[31] "National Bureau of Statistics of the People's Republic of China," http://www.stats.gov.cn.

[32] State Statistical Bureau, China Statistical Yearbook, China Statistical Press, Beijing, China, 2003-2012.

[33] State Statistical Bureau, China Energy Statistical Yearbook, China Statistical Press, Beijing, China, 2012. 


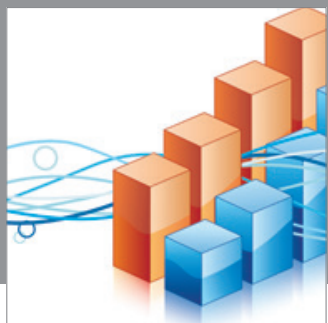

Advances in

Operations Research

mansans

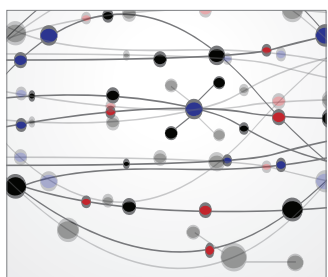

The Scientific World Journal
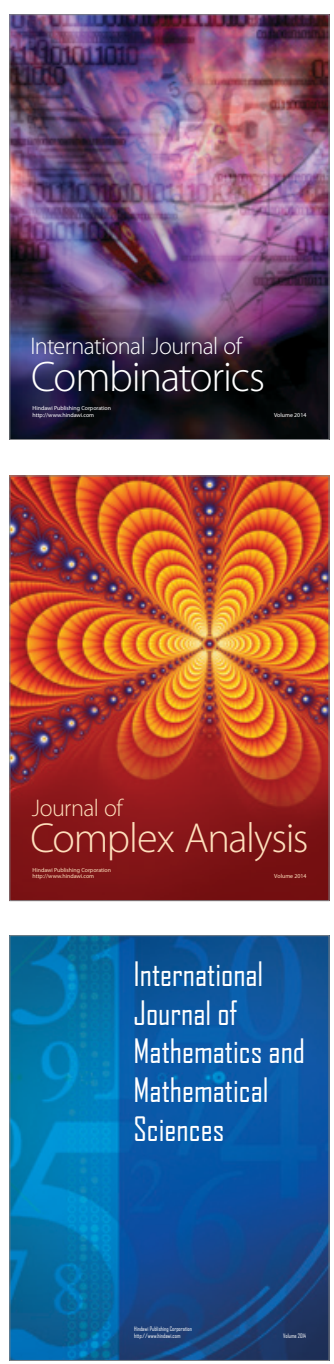
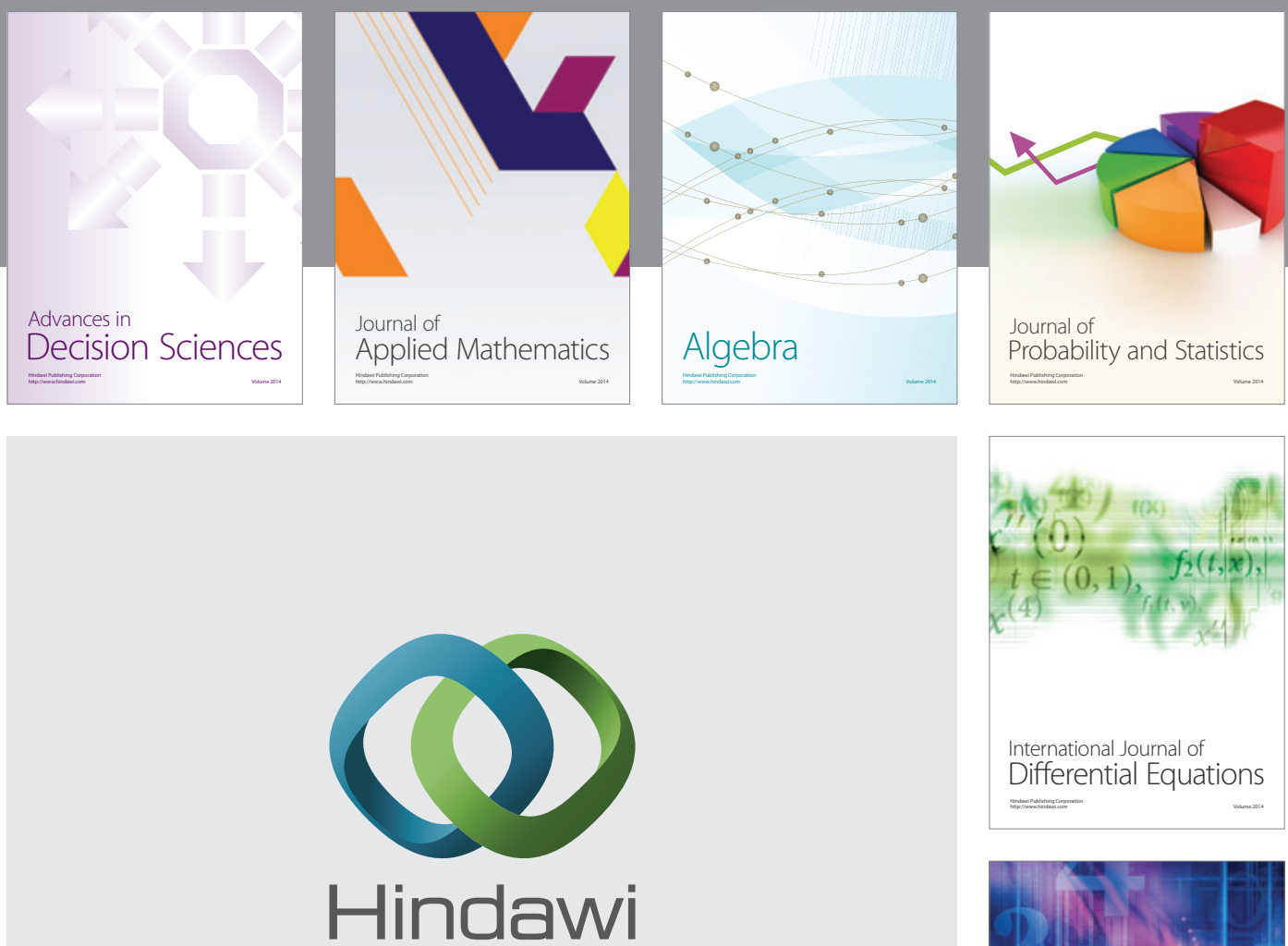

Submit your manuscripts at http://www.hindawi.com
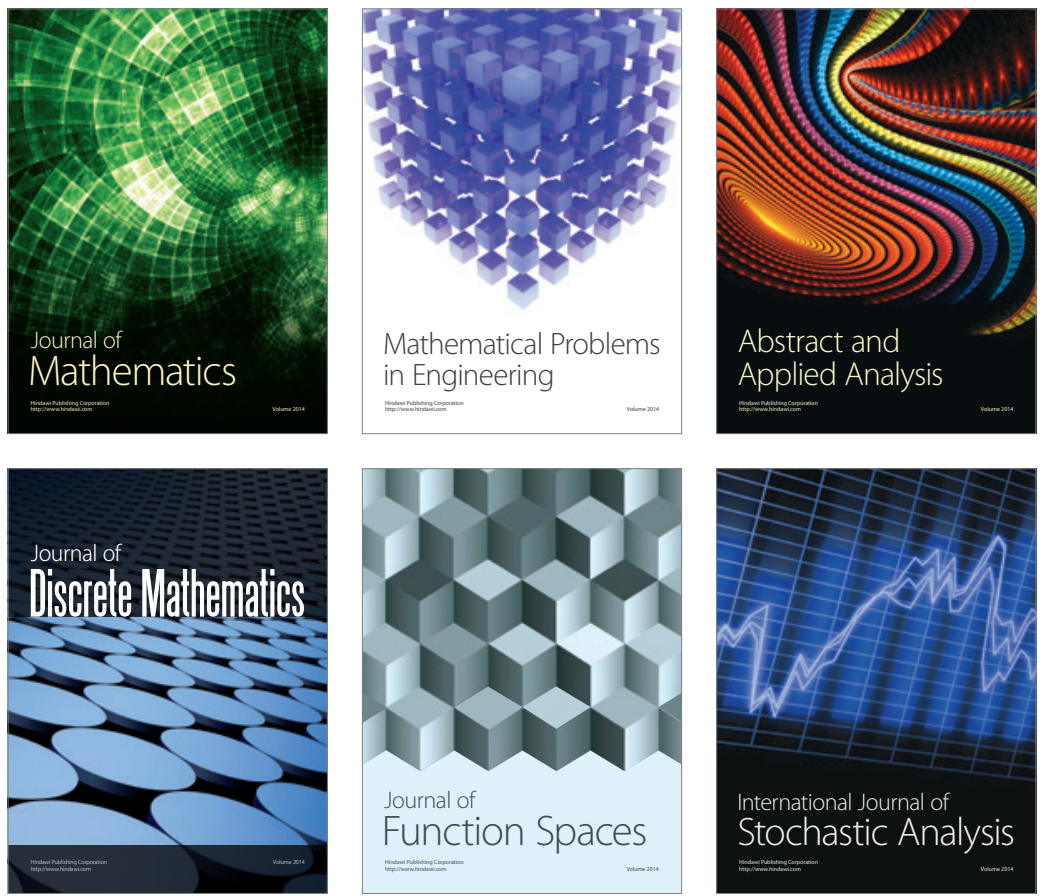

Journal of

Function Spaces

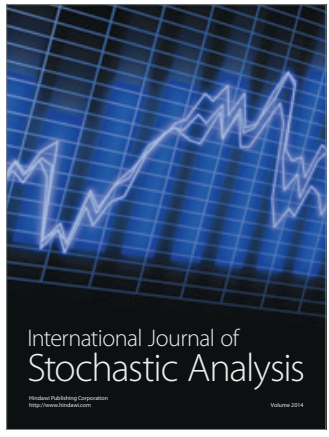

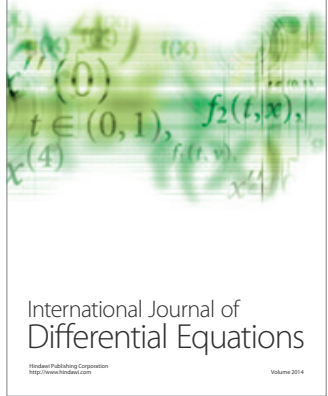
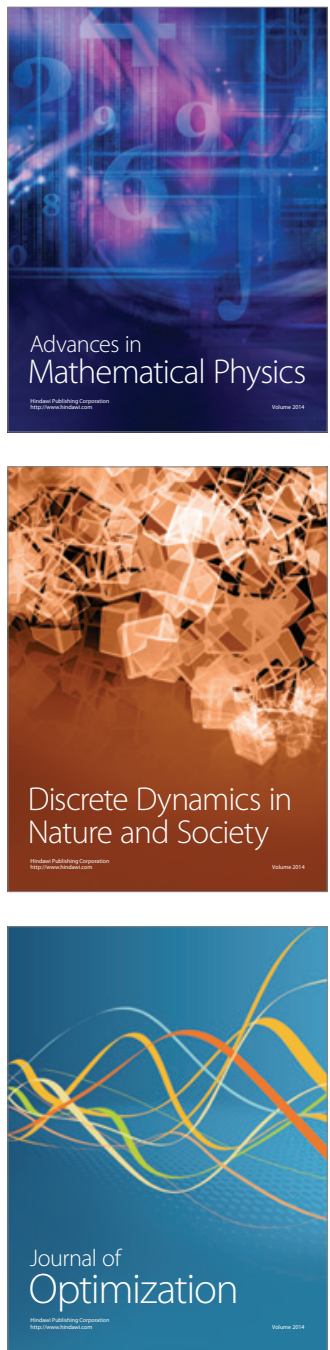